\title{
User-Centered Design: Developing the RELI Delivery System - a Low-Cost, Non-Electric, Pneumatic Infusion Pump
}

\author{
Elizabeth Abu-Haydar (D) \\ David Katuntu ${ }^{2, \dagger}$ \\ James Bauer' \\ Alec Wollen (iD) \\ Mike Eisenstein' \\ Jill Sherman-Konkle' \\ Anthony Roche ${ }^{3}$ \\ Michael Ruffo'
}

'PATH, Programs and Innovation Division, Medical Devices and Health Technologies, Seattle, WA, USA; ${ }^{2}$ PATH, Uganda Country Program, Kampala, Uganda; ${ }^{3}$ Department of Global Health, University of Washington, Seattle, WA, USA

†David Katuntu passed away on September I, 2020.
Correspondence: Elizabeth Abu-Haydar PATH, Programs and Innovation Division, Medical Devices and Health Technologies, 220 I Westlake Ave, Seattle, WA, 98I2I, USA

$\mathrm{Tel}+$ I $206285-3500$

Email eabuhaydar@path.org
Purpose: Infusion pumps are the preferred method for intravenous delivery of drugs and fluids, and an essential tool in health facilities. Their high cost, complexity and reliance on electricity pose serious challenges to wide-spread use, availability and access in low- and middle-income countries. PATH developed the RELI Delivery System (RELI), a low cost, non-electric infusion pump to address these challenges. Input collected from fifty-nine newborn and maternal care providers and from seven national level decision makers in Uganda was used to guide product development, further informing product design requirements, and optimal design features to best serve their needs.

Methods: A formative evaluation following a mixed methods approach including focus group discussions (FGDs), stakeholder interviews, and observations was used to collect data from end users.

Results: Stakeholders provided critical input on the RELI prototype design features, safety criteria, and contexts of use of infusion pumps, as well as recommendations for design refinements. Infusion systems are greatly needed but not readily available and their use is limited to well-resourced higher level facilities, even though the need is high in non-tertiary care hospital where patient volume is high, resources are scarce, power is inconsistent, and facilities are understaffed and overcrowded. Users expressed a need for an affordable and simple device with an intuitive user interface, clear instructions for use, and basic safety features.

Conclusion: The study provided important guidance for further design refinements based on input from respondents and confirmed the need for robust, affordable, infusion pumps that meet the requirements for use in low-resource settings.

Keywords: infusion pumps, low- and middle-income countries, user-centered design, product development, Uganda

\section{Introduction}

Infusion pumps are an essential medical device and the preferred intravenous system for the safe delivery of nutrients, fluids, and drugs to a patient. In high-resource countries, infusion pumps are common and are used in a broad range of therapeutic applications, including obstetric emergencies, antibiotic therapy, anesthesia, and palliative care. These devices are sophisticated pieces of equipment that have broad flow rate adjustability, complex software, and smart systems, including alarms. ${ }^{1}$ Infusion pumps require operator training and well-resourced and supported health systems. In low- and middle-income countries, availability of and access to infusion pumps are limited. These countries often lack the infrastructure and technical resources to support 
and sustain operation of electronic infusion pumps, and the financial resources to procure adequate numbers of these device to meet medical needs. ${ }^{2}$ The result is a significant gap in access to equitable and high-quality care for populations in resource-constrained settings.

This paper describes our user-centered approach to the design of the RELI Delivery System (RELI) a low-cost, non-electric, pneumatic infusion pump developed to improve performance of and access to infusion therapy in resource-constrained settings. Specifically, we report on findings from a user assessment conducted in Uganda to elicit feedback from maternal and newborn health care providers and other stakeholders on the perceived acceptability and usability of the RELI in maternal wards and newborn intensive care units (ICUs).

\section{Background}

Each year, obstetric and newborn emergencies account for roughly 290,000 maternal deaths and 2.5 million neonatal deaths worldwide, the majority occurring in low-resource settings (LRS). ${ }^{3,4}$ Many of these deaths could have been avoided if patients had access to timely and appropriate medical care. Equipping health workers with the tools they need is one critical element of improving the equity and quality of care. One such tool-ubiquitous in highresource settings - is the infusion pump. The World Health Organization recommends controlled intravenous delivery of common medications such as antibiotics, fluid therapy, and nutrition for critically ill newborns, as well as magnesium sulfate, oxytocin, and anesthesia for obstetric emergencies. $^{5-8}$ However, in LRS, the complexity and high cost of electric infusion pumps, as well as the lack of reliable electric power, impacts availability of and access to these pumps and in the quantities needed to meet the medical needs of patients. Non-electric, manual infusion systems fill a critical gap in LRS but are less than optimal, as they are more labor intensive, are less reliable, may require expensive proprietary disposables, and some systems lack flow rate and dose adjustability. ${ }^{9,10}$

These factors are critical barriers to providing highquality, effective medical care in cases in which timing and dose accuracy are crucial. Lack of access to appropriate equipment for controlled intravenous delivery can introduce patient safety concerns or limit the treatments clinicians can provide. In many low-resource settings, there is a need for safe, reliable, cost-effective, and appropriate infusion delivery systems that can be used not only in high-level facilities but also at lower levels of the health care system (primarily in rural areas), where they are most needed. ${ }^{11}$

Ideally, devices for these settings should be designed to be safe, robust, and easy to use, and have intuitive user controls and not require special disposable components or rely solely on electricity.

A landscape of competitive products was conducted in our early product development phase. A review of the United States Food and Drug Administration (USFDA) database to identified over 400 infusion pumps that are currently marketed in our target of low-income countries. Most of these devices are electric infusion pumps. We identified three predicate devices: the Springfusor syringe infusion pump, the Freedom60 syringe infusion system, and the Beeline System. Like the proposed RELI Delivery System, these three devices are syringe infusion systems, are non-electric, and mechanically powered. However, unlike these predicates, RELI does not require proprietary disposables, works with multiple syringe sizes, can deliver over a continuous range of flow rates, and is designed so that infusion rates can be adjusted during an infusion.

\section{User Assessment: Methods and Materials \\ Study Device}

Implementing a user-centered design approach that relied on expert advice and context analysis PATH (Seattle, Washington, USA) developed the RELI to be a robust, portable, non-electric, pneumatic infusion pump designed specifically for use in LRS.

The RELI is powered by an air tank pressurized by a built-in hand pump. The output pressure from the tank is controlled by a precision regulator. The regulated air drives a piston that pushes the syringe, delivering the medicine or fluid. The combined effects of the input air pressure to the piston and the resistance provided by the movement of hydraulic fluid through the flow-restricting tubing controls the rate at which the piston moves and hence the flow rate of the fluid delivered by the syringe. ${ }^{12}$ The user controls the flow rate by adjusting the precision regulator with the flow rate adjustment knob. The air pressure in the tank and the air pressure applied to the piston are read from two dial gauges on the front of the device. Initiation and cessation of the infusion are controlled by a pneumatic start/stop switch. A reset valve allows the user to adjust the position of the syringe pusher before the start of infusion. (See Figure 1.) 


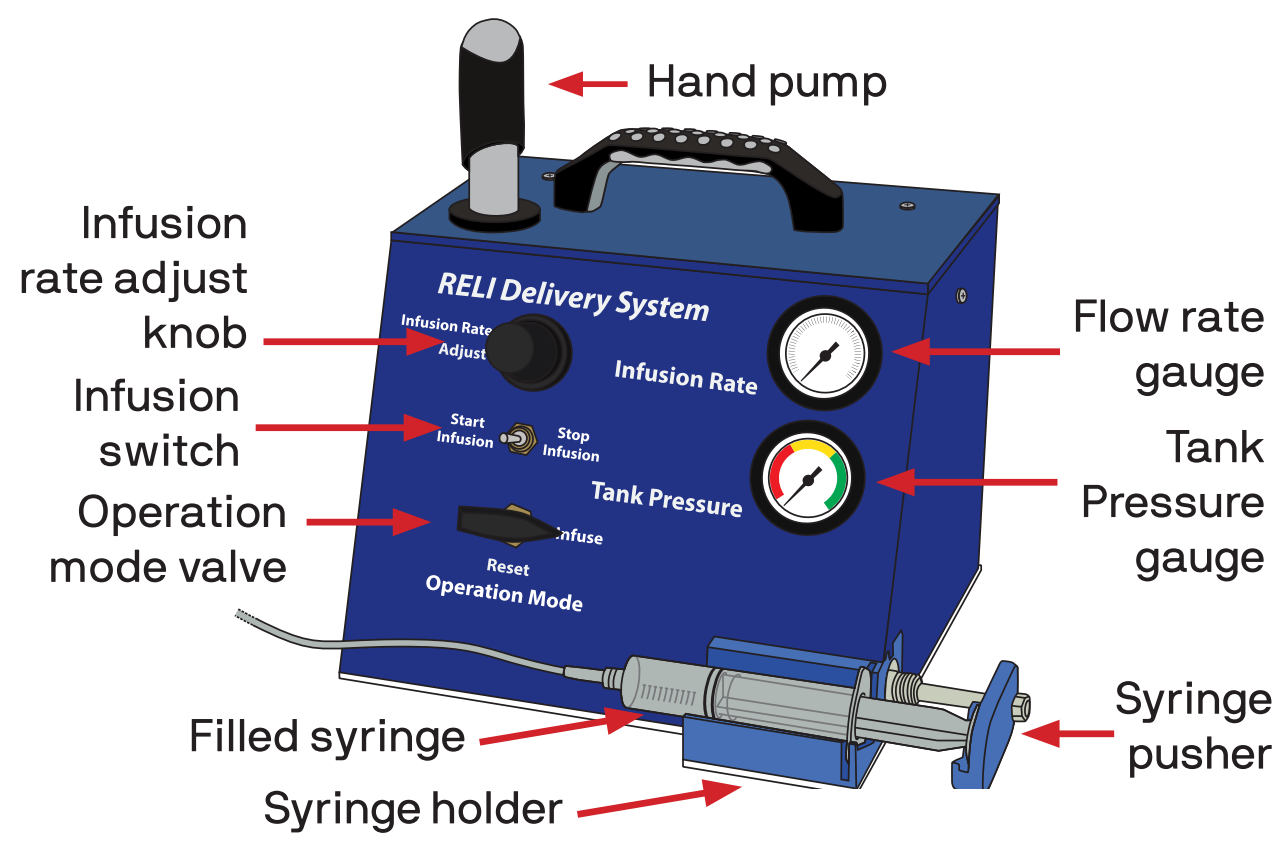

Figure I Illustration of a prototype of the RELI Delivery System.

Similar to conventional infusion systems, the RELI features precise flow control and adjustment. Unlike the conventional systems, it does not require a software-based user interface (Figure 2), sidestepping the most common safety issues related to user interactions with infusion pumps. ${ }^{13}$ Furthermore, by not using electronic components, software, or sources of electricity (such as batteries or mains power), or requiring specialized tubing, this non-electric RELI device could cost significantly less than an electric device while overcoming the challenges posed by non-electric infusion systems.

\section{Study Objectives and Design}

The primary objective of the study was to gather input from health care providers and experts in Uganda on the key features of the RELI prototype and its appropriateness for use cases identified by the stakeholders. An iterative, user- centered approach from concept development through this user evaluation phase informed our understanding of those primarily responsible for administering infusions in health facilities, challenges they currently face, and how the RELI can best be designed to support these needs. Using this approach throughout the product development lifecycle is intended to result in a final design that assures the administration of safe infusions while addressing human factors requirements. The ultimate goal is to design a product that meets user needs and addresses the four "A's" - appropriateness, affordability, availability, and awareness — which will support successful introduction of this innovation.

A formative evaluation following a mixed methods approach was used to collect information and feedback from end users, including focus group discussions (FGDs), stakeholder interviews, device demonstrations, and secondary document reviews. Data were collected from April 2018 through May 2018.

\begin{tabular}{|l|l|l|l|l|l|l|l|l|l|}
\hline & $\begin{array}{l}\text { Electricity } \\
\text {-free }\end{array}$ & $\begin{array}{l}\text { Adjustable } \\
\text { flow rates }\end{array}$ & $\begin{array}{l}\text { Precision } \\
\text { flow rates }\end{array}$ & $\begin{array}{l}\text { Low-cost } \\
\text { device }\end{array}$ & $\begin{array}{l}\text { Low-cost } \\
\text { consumables }\end{array}$ & $\begin{array}{l}\text { Nonproprietary } \\
\text { consumables }\end{array}$ & $\begin{array}{l}\text { Simple } \\
\text { interface }\end{array}$ & $\begin{array}{l}\text { Robust } \\
\text { hardware }\end{array}$ & $\begin{array}{l}\text { Software-based } \\
\text { user interface }\end{array}$ \\
\hline Electronic infusion pumps & $\times$ & $\checkmark$ & $\checkmark$ & $\times$ & $\checkmark$ & $\checkmark$ & $\times$ & $\checkmark$ \\
\hline Disposable infusion pumps & $\checkmark$ & $\times$ & $\times$ & $\checkmark$ & $\times$ & $\checkmark$ & $\checkmark$ & $\checkmark$ \\
\hline RELI Delivery System & $\checkmark$ & $\checkmark$ & $\checkmark$ & $\checkmark$ & $\checkmark$ & $\checkmark$ & $\checkmark$ & $\checkmark$ \\
\hline
\end{tabular}

Figure 2 Key features of infusion pump categories. 


\section{Study Sites}

Data were collected in two districts in Uganda: Jinja and Kampala. The Jinja District is located in the eastern region of the country. Administrative units in the district include 200 counties, 11 sub-counties, and 69 parishes. The population was approximately 470,000 in 2014 , of which nearly 300,000 reside rural areas, with farming as the main source of income. ${ }^{14}$ FGDs and interviews were conducted with staff at Jinja Referral Hospital, Iganga District Hospital, and the Bundondo level IV health center.

The Kampala District, located north of Lake Victoria, has five sub-counties and 76 parishes and encompasses Kampala City, the capital of Uganda. The population was approximately 7 million in 2020. ${ }^{15}$ Feedback was collected from staff of Naguru District Hospital and Mulago National Referral Hospital.

The targeted facilities were identified as government facilities representative of rural and urban areas and of different levels of public-sector health care in Uganda. All participating facilities had infusion therapy capacity and expertise at the time of the study.

\section{Study Participants}

Medical officers, nurses, nurse midwives, and attending physicians providing care to women, newborns, and children and who were familiar with infusion systems, were selected for participation. A convenience sampling approach was used to recruit providers present at the facility at the time of the planned visits. The FGDs were held at Jinja Regional Referral Hospital in Jinja District and Naguru District Hospital in Kampala District. Individual semi-structured interviews were conducted with medical specialists, product development experts, and officials with expertise in regulatory requirements and supply chain processes in Kampala District. Medical specialists included obstetricians and gynecologists, anesthesiologists, and neonatologists. All respondents provided written consent prior to participation in the FGDs and the interviews. Verbal consent to record the FGD sessions and take pictures was obtained from all participants. In all, 48 health care providers participated in the FGDs, and interviews were conducted with 11 physicians at Mulago National Referral Hospital in Kampala, three biomedical engineers at Makerere University, three government officials at the Ministry of Health, and one member of the National Advisory Committee on Medical Equipment (NACME), based in Kampala. The purpose of the data collection was to learn about current infusion pump use in the health facilities in Uganda, and to gather end user input on the RELI features and form factor to inform design optimization and ensure the syringe driver is acceptable, easy to use, feasible, and meets the needs of both providers and the health system.

\section{Study Tools}

Guides for conducting FGDs and semi-structured interviews were developed for use in gathering information. Prior to the start of the FGDs and the individual interviews, the research team described the device and demonstrated how it functions. Participants were invited to handle the device and comment, following the group discussions and the interviews. The FGDs were conducted by a trained facilitator and lasted between 60 and 70 minutes. The interviews took between 60 and 90 minutes each. Prior to the start of the study, an extensive review of key documents pertaining to medical devices in Uganda was undertaken. These included a review of the national Essential Medicines and Health Supplies List for Uganda (2016), the national functional inventory for medical equipment, the Health Sector Development Plan 2015/16-2019/20, the National Medical Equipment Policy, the lists of approved medical devices by level of health facility (2015), the Roadmap for Accelerating the Reduction of Maternal and Neonatal Mortality and Morbidity in Uganda (2007-2015), the Annual Health Sector Performance Report: Financial Year 2015/2016, and the lists of approved medical equipment for public procurement and reimbursement (2015-2016). The document review provided insight into current procurement and regulatory requirements for infusion pump use, as well as policy around certification, training, and which cadres of workers are allowed to administer drugs using infusion systems.

For the assessment in Uganda, PATH brought a working RELI prototype to demonstrate functionality and collect user feedback on the device design.

\section{Findings}

Our research questions focused on two themes: (1) user experiences with current infusion systems; (2) user input on specific features of the RELI interface. Results from the FGDs and key informant interviews were organized under these two themes. Information extracted from the document review was verified during the FGDs and interviews.

\section{User Experiences with Current Infusion Systems}

Focus group participants $(\mathrm{n}=48)$ were predominantly nurses and nurse midwives with several years of training, chosen for their experience working in critical care, and with infusion therapy. 
Also present for the FGDs were medical officers and a few physicians. These providers follow well-established protocols that guide infusion regimens and they are responsible for the administration of infusions of medications and rehydration fluids based on the treatment order prescribed by the medical officers in charge. Infusion pumps are a scarce commodity in their facilities, largely due to cost. As a result, infusion pump use is restricted to services that address the most acute needs, including intensive care units, neonatal care units, operating theaters, and in a few cases, obstetric wards. For example, 100-bed Naguru District Hospital (which since our study has been designated as a regional hospital) had a total of six pumps: two in the operating theater, two in the critical care ward, one in the medical ward, and one in the ICU. Respondents shared concerns that the shortage of infusion pumps meant all patients in need of intravenous therapy could not benefit from it. The study team observed nurses using a basic infusion set with a micro-drip system to infuse fluids and medications. They also observed use of burettes that acted as drip chambers and metered out the required amount of fluid or drug needed, using a roller clamp to control the rate of the infusion. With few infusion pumps available for use, these make-shift systems are necessary, but all participants agreed these systems are not precise, are labor intensive, and require constant monitoring to ensure safety and efficacy of treatment. This is particularly true in busy neonatal wards and ICUs, where precision is critical and health workers are overstretched. The majority of FGD participants cited that smaller hospitals, most of which are located in rural areas, have the least access to infusion therapy but are in the greatest need, due to high patient volumes, scarce resources, inconsistent power supply, and understaffed and overcrowded facilities. They acknowledged that most of the electric infusion pumps they use would not be affordable for smaller hospitals, are not built for their harsh environments, and are not sustainable in these facilities with generally weak maintenance infrastructures.

Key informants $(n=11)$ interviewed at Mulago National Referral Hospital in Kampala included anesthesiologists, obstetricians, and neonatologists. The physicians confirmed that infusion pumps are mainly used for sedation and administration of vasopressors and inotropes, fluids, palliative care, and antibiotics. All interviewees stated that non-electric pumps might not be needed in national referral hospitals, particularly not in their ICUs and operating theaters, as these hospitals are well equipped and have backup generators. However, an affordable, mechanical pump like the RELI could meet a critical need in medical wards where the numbers of patients are high and cost constraints limit the availability of essential equipment.
In general, interview participants stated providers are overworked; services are understaffed; and equipping health workers with appropriate tools that are easy to use, robust, and are priced to afford in the quantities needed would support their work. They emphasized that training on the use of infusion pumps, the availability of clear and illustrated instructions for use, and provisions for maintenance and repair are critical elements to ensure sustained, safe, and effective use.

Discussions with biomedical engineers at Makerere University, and government officials provided information about current processes for procurement and distribution of medical equipment in Uganda. Input from this cadre of experts is critical in informing design, specifications, requirements, and cost constraints. These stakeholders confirmed that budgets for medical equipment are limited, and while procurement of medical devices is based on the government's assessment of need and device specifications, it is predominantly dictated by the cost of the equipment. Discussions with these experts further confirmed the need for a low-cost infusion system. The unique value proposition and low target price point of the RELI Delivery System will be key differentiating factors. Our goal is to increase access to infusion therapy by providing an easy-to-use, electricity-free, syringe driver, at an affordable price. At this early stage in development, a target end-user price between US\$500 and US $\$ 1000$ has been set. This target is based on the prices of available competitive products that range between US\$600 and US\$2000.

\section{User Input on the RELI Delivery System Interface}

Prior to gathering input from FGD participants and key informants, the study team conducted a demonstration of the RELI prototype. Following the discussions and interviews, participants were invited to handle and use the device.

Throughout the discussions, respondents provided critical input on device design features, safety criteria, and contexts of use. Participants recommended that the device be intuitive, easy to use, robust, and, above all else, safe and effective in providing therapy with correct dosages and infusion rates.

"The pump must be extremely robust; things break all the time here". $\sim \mathrm{ICU}$ nurse

Keep it simple, safe, and effective. Do not try to make a device that does everything. The need is so great for neonates and women that you can start there and make a huge impact. $\sim$ Physician

Table 1 summarizes user input on specific features of the RELI and potential design modifications to address user 
Table I User Input on Key Features of the RELI Delivery System

\begin{tabular}{|c|c|c|}
\hline $\begin{array}{l}\text { Design } \\
\text { Feature }\end{array}$ & User Input & Resulting Design Consideration \\
\hline $\begin{array}{l}\text { Size and } \\
\text { weight }\end{array}$ & $\begin{array}{l}\text { The device needs to be smaller and lightweight. Space is at } \\
\text { a premium, especially in intensive care units. The device must be } \\
\text { light enough to be easily transported around the wards. }\end{array}$ & Select materials and components for size and weight reduction. \\
\hline $\begin{array}{l}\text { Portability } \\
\text { and stability }\end{array}$ & $\begin{array}{l}\text { The handle on the device is useful and makes it portable Infusion } \\
\text { pumps are placed on carts, mounted on intravenous poles, or } \\
\text { used for transport in ambulances. The device must be able to be } \\
\text { attached securely to a pole or cart so that infusions are not } \\
\text { affected or interrupted by movement. }\end{array}$ & $\begin{array}{l}\text { Select materials and components for portability. } \\
\text { Add a mounting system and conduct vibration testing. }\end{array}$ \\
\hline Durability & $\begin{array}{l}\text { The device must be designed to withstand rough environmental } \\
\text { conditions and handling (humidity, dust, movement, water/ } \\
\text { fluids). }\end{array}$ & Select housing material and design geometry for robustness. \\
\hline $\begin{array}{l}\text { Infection } \\
\text { control }\end{array}$ & $\begin{array}{l}\text { The device must be easy to clean; the design should be simple, } \\
\text { with smooth surfaces on the knobs and pump. }\end{array}$ & Design geometry and select materials for ease of cleaning. \\
\hline $\begin{array}{l}\text { Bicycle/ } \\
\text { manual } \\
\text { pump }\end{array}$ & $\begin{array}{l}\text { Pressurizing the device must be intuitive, easy, and rapid. Initial } \\
\text { reactions to the mechanical (bicycle) pump indicated that it } \\
\text { seemed awkward and difficult to activate, and excessive } \\
\text { pumping may be required to reach the required pressure. After } \\
\text { hands-on experience with the pump, input from nurses } \\
\text { indicated that it was easier to use than it looked. }\end{array}$ & $\begin{array}{l}\text { Investigate use of an alternative angle/location for the pump for } \\
\text { easier handling and pumping. } \\
\text { Provide detailed, illustrated instructions on pump activation and } \\
\text { estimated time to reach minimum pressure. }\end{array}$ \\
\hline Pump gauge & $\begin{array}{l}\text { Health workers must be confident that pressure would be } \\
\text { maintained for the duration of the infusion. Strong preference } \\
\text { was expressed for a color-coded (universal red, yellow, green) } \\
\text { pressure gauge to provide visual confirmation that adequate } \\
\text { pressure levels were reached and would be maintained. }\end{array}$ & Design a custom gauge for easier interpretation. \\
\hline $\begin{array}{l}\text { Flow rate } \\
\text { gauge }\end{array}$ & $\begin{array}{l}\text { The flow rate gauge must be large enough, so it is visible in low- } \\
\text { light conditions and from a distance. A digital display was } \\
\text { suggested to ensure that precise flow rates are being set. }\end{array}$ & $\begin{array}{l}\text { Design a custom gauge that is large enough to be easy to read in } \\
\text { varying working conditions. A digital gauge would require } \\
\text { a special non-electric mechanism such as a manual crank or } \\
\text { solar- powered chip. }\end{array}$ \\
\hline Alarms & $\begin{array}{l}\text { An alarm should alert for occlusions and changes in infusion } \\
\text { rates. This feature was deemed particularly critical in settings } \\
\text { with shortages of providers and high volumes of very sick } \\
\text { patients. }\end{array}$ & $\begin{array}{l}\text { Investigate the feasibility of a mechanical alarm that is durable } \\
\text { and affordable. }\end{array}$ \\
\hline Syringe size & $\begin{array}{l}\text { The device must be designed for use with a multitude of } \\
\text { syringe sizes. The most common syringe sizes are } 10 \mathrm{~mL} \text { and } \\
20 \mathrm{~mL} 50-\mathrm{mL} \text { syringes are expensive and not as common. } \\
\text { Syringes with luer lock tips are rare in most facilities and the } \\
\text { design of the syringe holder should take that into } \\
\text { consideration. }\end{array}$ & $\begin{array}{l}\text { Develop a design that enables use of syringes ranging from } \\
10 \mathrm{~mL} \text { to } 60 \mathrm{~mL} \text { in size. }\end{array}$ \\
\hline $\begin{array}{l}\text { Syringe } \\
\text { position }\end{array}$ & $\begin{array}{l}\text { Health care providers expressed concern about the position of } \\
\text { the syringe pusher-that it could lead to damage or } \\
\text { displacement during infusion. }\end{array}$ & Design a protective guard for the syringe pusher. \\
\hline
\end{tabular}


Table I (Continued).

\begin{tabular}{|l|l|l|}
\hline $\begin{array}{l}\text { Design } \\
\text { Feature }\end{array}$ & User Input & Resulting Design Consideration \\
\hline $\begin{array}{l}\text { Instructions } \\
\text { for use }\end{array}$ & $\begin{array}{l}\text { Health workers reported the need for illustrated step-by-step } \\
\text { instructions. These are especially critical in facilities with high } \\
\text { staff turnover. Illustrated instructions should be attached to the } \\
\text { device and easy to see. }\end{array}$ & $\begin{array}{l}\text { Collect user feedback on quick reference use instructions and } \\
\text { device labeling to ensure they are appropriate, understandable, } \\
\text { and acceptable }\end{array}$ \\
\hline $\begin{array}{l}\text { Infusion } \\
\text { volume }\end{array}$ & $\begin{array}{l}\text { The device is limited to delivery of smaller infusions (up to } \\
60 \mathrm{~mL} \text { ). A device with capacity for larger-volume infusions (up } \\
\text { to } 500 \mathrm{~mL} \text { ) would meet a great need. }\end{array}$ & Consider a design that incorporates large infusion volumes. \\
\hline
\end{tabular}

concerns. There was no significant difference in the feedback we received from nurses, physicians, policymakers, and engineers.

\section{Discussion}

While ubiquitous in high-resourced medical facilities, in Uganda electric infusion pumps are mostly found in tertiary centers, large regional hospitals, and some district hospitals - but not in the quantities needed to meet the medical needs of the populations they serve, primarily due to cost and unsuitability for low-resource settings. Electric infusion pumps are very rarely found in rural hospitals. Generally, few commercial devices are designed to be rugged and suitable for environments with the high temperatures and high humidity levels found in many lowand middle-income countries. Devices that cannot withstand these conditions stop working and are often not repaired or replaced, leaving health facilities with limited capacity to provide infusions to patients. ${ }^{16,17}$ Additionally, the backup battery life of electronic infusion pumps may not be optimized for such settings, particularly where power supply is inconsistent. Innovation and design of appropriate medical technologies that address these challenges continues to be a high priority for policymakers, donors, health care providers, and key stakeholders.

The user input collected in Uganda was part of a continuous iterative design approach that led to the current prototype. Respondents brought critical clinical expertise that informed our engineering and technical experts and informed critical changes to the user interface and functionality of the RELI prior to the next phase of clinical validation of the device. Something as simple as including clear, illustrated user instructions (either printed or attached securely to the device) that can provide a quick reference for nurses providing infusion therapy, can be extremely important. Descriptions of physical environment in which the device will be used highlighted the need for a compact and portable unit that can be safely anchored to ensure safe administration in crowded ICUs, medical wards, and medical transport vehicles. Infection control was mentioned as a high priority, and respondents stressed the need for smooth surfaces on knobs and handles to facilitate infection control measures. Experts called particular attention to the need for a device that ensures consistent flow rates and maintains pressure, which will lead to major engineering modifications to the next-generation RELI design. Furthermore, gathering information about supply chain and regulatory requirements from nonmedical personnel was also critical for the project, and will support the choice of manufacturing partner and price points for an affordable product that will be more likely to be purchased and used by country programs.

Overall, health care providers and other stakeholders in Uganda gave critical input on the RELI's design features, safety criteria, and context of use. They expressed a strong need for robust, affordable infusion pumps that meet the requirements for use in low-resource settings, which will provide important direction for further design refinements.

\section{Ethical Approval and Consent to Participate}

Ethical approval for this study was obtained in May 2018 from the Mbarara University of Science and Technology Research Ethics Committee (approval registration \#05/0518). Participants in the study were required to provide written consent prior to the interviews and FGDs. Verbal consent to record the sessions and take photos for use in reports was collected from each participant.

\section{Acknowledgments}

We thank Robbie Adams and Jessica Bolich for their help with research and editorial assistance. We also thank Zach 
Clemens, Dan Myers, and Elizabeth Griffin for their technical expertise and input. Mike Eisenstein recently moved to Equalize Health, 695 Minnesota Street, San Francisco, CA 94107.

\section{Author Contributions}

All authors contributed to data analysis, drafting or revising the article, have agreed on the journal to which the article will be submitted, gave final approval of the version to be published, and agree to be accountable for all aspects of the work.

\section{Funding}

Support for this project was provided by the United Kingdom (UK) Foreign, Commonwealth and Development Office (FCDO) through the Devices, Diagnostics, and Drugs to Address Women's Needs ( $\mathrm{D}_{3} \mathrm{AWN}$ ) award to PATH and through the generous support of the Saving Lives at Birth partners (funding by USAID under a Saving Lives a Birth Grand Challenges grant) The contents are the responsibility of PATH and do not necessarily reflect the views of FCDO, the UK government or the Saving Lives at Birth partners. PATH developed the study design, collected the data, and led the analysis and decision to publish, and PATH staff prepared the original content of the manuscript.

\section{Disclosure}

The authors have declared no competing financial interests exist. The authors reported no potential conflicts of interest for this work.

\section{References}

1. Lönnqvist PA. How continuous are continuous drug infusions? Intensive Care Med. 2000;26(6):660-661. doi:10.1007/ s001340051229

2. Mundle S, Regi A, Easterling T, et al. Treatment approaches for preeclampsia in low-resource settings: a randomized trial of the Springfusor pump for delivery of magnesium sulfate. Pregnancy Hypertens. 2012;2(1):32-38. doi:10.1016/j.preghy.2011.09.002
3. World Health Organization. Maternal mortality [key facts]. Geneva, Switzerland: World Health Organization; September 19, 2019. Available from: https://www.who.int/en/news-room/fact-sheets /detail/maternal-mortality. Accessed September 24, 2020.

4. World Health Organization. Newborns: improving survival and well-being [key facts]. Geneva, Switzerland: World Health Organization; September 19, 2019. Available from: https://www. who.int/news-room/fact-sheets/detail/newborns-reducing-mortality. Accessed September 24, 2020.

5. Maine D, Patsy B, Lobis S, Fortney J. Monitoring Emergency Obstetric Care: A Handbook. Geneva, Switzerland: World Health Organization; 2009.

6. World Health Organization. Pocket Book of Hospital Care for Children. Geneva, Switzerland: World Health Organization; 2013.

7. World Health Organization. Infusion Pumps. Geneva, Switzerland: World Health Organization; 2012.

8. World Health Organization. Managing Newborn Problems: A Guide for Doctors, Nurses, and Midwives. Geneva, Switzerland: World Health Organization; 2003.

9. Skryabina EA, Dunn TS. Disposable infusion pumps. Am J Health Syst Pharm. 2006;63(13):1260-1268. doi:10.2146/ajhp050408

10. Pierce ET, Kumar V, Zheng H, Peterfreund RA. Medication and volume delivery by gravity-driven micro-drip intravenous infusion: potential variations during "wide-open" flow. Anesth Analg. 2013;116 (3):614-618. doi:10.1213/ANE.0b013e31827bc235

11. Shah K, Skerrett E, Nojoomi M, et al. Maji: a new tool to prevent overhydration of children receiving intravenous fluid therapy in low-resource settings. Am J Trop Med Hyg. 2015;92(5):1053-1058. doi:10.4269/ajtmh.14-0495

12. Guelig D, Bauer J, Wollen A, et al. Design of a novel, adjustable flow rate, reusable, electricity-free, low-cost syringe infusion pump. J Med Devices. 2017;11(4):041006 (6 pages). doi:10.1115/1.4037935

13. US Food and Drug Administration. Infusion pumps [page on the Internet]. Available from: http://www.fda.gov/MedicalDevices/ ProductsandMedicalProcedures/GeneralHospitalDevicesandSupplies/ InfusionPumps/default.htm. Accessed February 9, 2016.

14. Uganda Bureau of Statistics. The National Population and Housing Census 2014: Main Report. Kampala, Uganda: Uganda Bureau of Statistics; 2016:Vol. 50.

15. Populationstat.com. Kampala, Uganda Population (2020) Population Stat. [online]; 2020. Available from: https://population stat.com/uganda/kampala. Accessed September 24, 2020.

16. Perry L, Malkin R. Effectiveness of medical equipment donations to improve health systems: how much medical equipment is broken in the developing world? Med Biol Eng Comput. 2011;49(7):719-722. doi:10.1007/s11517-011-0786-3

17. The World Health Organization: medical devices: managing the mismatch- 2010. Available from: https://apps.who.int/iris/bitstream/ handle/10665/44407/9789241564045_eng.pdf?sequence=1. Accessed May 12, 2021.
Medical Devices: Evidence and Research

\section{Publish your work in this journal}

Medical Devices: Evidence and Research is an international, peerreviewed, open access journal that focuses on the evidence, technology, research, and expert opinion supporting the use and application of medical devices in the diagnosis, monitoring, treatment and management of clinical conditions and physiological processes. The identification of novel devices and optimal use of existing devices

\section{Dovepress}

which will lead to improved clinical outcomes and more effective patient management and safety is a key feature of the journal. The manuscript management system is completely online and includes a very quick and fair peer-review system. Visit http:// www.dovepress.com/testimonials.php to read real quotes from published authors. 